\title{
TRUNK ASYMMETRY AND SPRUCE WOOD RESONANT PROPERTIES VARIABILITY WITH RESPECT TO THE CARDINAL POINTS AND THE TREE HEIGHT
}

\author{
Vladimir Ilyich Fedyukov* \\ Volga State University of Technology, Russian Federation \\ Ekaterina Yurevna Saldaeva \\ Volga State University of Technology, Russian Federation \\ Maria Sergeyevna Chernova \\ Volga State University of Technology, Russian Federation \\ Vasilii Yurevich Chernov \\ Volga State University of Technology, Russian Federation
}

Decks of musical instruments are developed from sawn wood products of strictly radial cutting and, as a rule, for this purpose the wood is selected according to the radius of a trunk from a certain forest site. An important factor for manufacturing high-quality (custom-made) musical instruments is the account of position of the best zone of a tree trunk with respect to the cardinal points. Observance of this condition becomes complicated by the fact that frequently trunks have the form of an abnormal cylinder with a displaced and curved axis (asymmetry). Physical and mechanical properties of wood vary greatly along trunk height; it is sometimes difficult to define the part of trunk wood with the best acoustic parameters. The paper presents the following research results: external and internal asymmetry of spruce trunks; macrostructures and acoustic constants of wood on northern and southern sides of a trunk; changes of cross-section sound velocity in wood along tree height and depending on the trunk diameter; dependence of sound velocity in wood on biometric data of a trunk. Based on the results of the experiment done, the estimation of cardinal points and position of wood at trunk height influencing the parameters of its 'musicality' is made. The data obtained and conclusions of the research are of scientific interest and bear practical recommendations for correct selection of wood with unique acoustic properties from a spruce-tree trunk. Key words: Ascoustic constant, Internal and external tree trunk asymmetry, Resonant properties, Spruce growing, Wood macrostructure, Wood density

\section{INTRODUCTION}

No practical value is usually given to and change of wood properties depending on its facing the cardinal points is not taken into account with forest products of general and special purpose, including timber blanks and parts for manufacturing musical instruments for wide use. It is considered, e.g., that the cardinal points do not considerably influence the contents of late wood, and eccentric growth of a trunk is caused mainly by the impact of other factors: non-uniform development of a tree crown, exposure to wind, etc. [19]. Meanwhile, in ancient times, violins and other musical instruments master craftsmen paid special attention to selection of material from a tree-trunk for making custom-made instruments. Many of them preferred wood from the northern side of a tree trunk, and they saw 'the best firewood'in the southern part of a tree trunk [10]. There are practically no special scientific research works concerning dendro-acoustical differences of wood depending on the cardinal points. However there are data on macrostructure and anatomical structure peculiarities of different sectors of a tree trunk. It is also necessary to note, that from time immemorial there is a standard opinion on tree annual rings orientation with respect to the cardinal points: the part of a tree facing the south has wider annual rings than the parts facing other cardinal

*Volga State University of Technology, 424000, The Republic of Mari El, Yoshkar-Ola, Lenin Sq., b. 3., Russia 
points. This opinion is considered so constant that it is assigned a value of a natural surveyor's compass for defining the meridian fora given locality. Some authors attempted to check up the position of poles in the geological past and courses of carboniferous zones to find out conditions of their formation by studying standing fossil stubs in order to define the directions of mineral coals search [14].

From the view point of wood science, the work of N.L. Kossovich is of great interest presenting the following results through the example of research of the pine and the spruce [13]:

- during the first 30 years of growth the contents of late wood prevails on the southern side of a pine tree trunk at height of $6.5 \mathrm{~m}$ when, in the opinion of the author, the influence of the cardinal points on formation of macrostructure is shown more strongly, whereas at height of $13.1 \mathrm{~m}$ it is not observed, while at the age of more than 30 years the difference is observed towards both increase and decrease at these heights;

- onthesouthernsideofatrunkfalseannualrings occur more often, namely, 7 times in 8 cases:

- at an early age, approximately up to 10 years, wider annual rings appear on the southern part of a trunk, and at the age over 10 years they are found on the northern one; in the latter case this difference makes 3-4 \%;

- it is important to note, that in comparison of a shade-tolerant spruce and a light-demanding pine the difference of the average contents of late wood on the northern and southern sides of a trunk was not found out;

- there is an essential difference between the northern and the southern parts of a pine trunk in anatomical structure. For example, wider tracheids occur more often on the southern side and narrow ones, on the contrary, occur relatively less often; the maximum southern tracheids lay in the group of 30-40 microns, and the northern ones lay within the limits of $20-30$ microns.

The author describes intrinsic peculiarities of the pine and the spruce in view of the contents of vertical resin ducts. So, if the pine does not have sharp difference between the northern and the southern sides in this respect, spruce wood has much more vertical resin ducts on the northern side of a trunk; in the bottom part of a tree this difference increases more than threefold.
In recent years there were scientific results, confirming distinction of a gain of annual growth rings of wood on the example of a white acacia; on the southern and east parties of a trunk annual growth rings are much wider, than on the northern and western parties; the author assumes the reason of such distinction in day length and temperature of a cambial layer on parts of the world [12].

The scientific results submitted above confirm the necessity of purposeful studying of spruce wood within the framework of the research under consideration. The choice of the material given is caused by its wide application in the manufacture of many kinds of musical instruments. This is connected with the fact that macrostructure parameters (width of annual rings and late wood contents) are included in national standards of many countries as the basic criterion for selecting resonant forest products. The role of microstructure in formation of acoustic properties of wood is studied and confirmed in early research works which results are published last century $[02,11,18]$ and a current one $[05,06,07]$. The data on fluctuation of wood density values inside a tree trunk are of great practical interest under selection of material for manufacturing resonant assortments; material porosity which substantially influences acoustic parameters, e.g., velocity of sound and its frequencyamplitude response is connected to density. Therefore, in the work under consideration, density was studied in interrelation with the dynamic modulus of elasticity and the sound velocity included in the formula for defining acoustic constant as the basic criterion of wood 'musicality' according to formulas for sound velocity and Young's dynamic modulus in wood.

\section{MATERIALS AND METHODS}

The research was carried out on the territory of Kirov and Perm regions belonging to the zone of taiga woods of Russia in respect of forest growth conditions. Research plotsarepresented bystands of mature spruce trees at the age of 120-150 years and of II-III bonitet classes in view of productivity.

The asymmetry was studied on trunk collars of circular saw cuts $50 \mathrm{~mm}$ thick from 9 average spruce trees (characteristic average ones for the forest research plots) at trunk height of $1.3 \mathrm{~m}$ and at its different relative heights: $0.2 \mathrm{H} ; 0.5 \mathrm{H}$; $0.7 \mathrm{H}$ (Figure 1), where $\mathrm{H}$ is the height of a tree. 




Figure1: Sample selection chart

Before average trees cutting the marks were made on their trunks approximately at breast height with respect to four cardinal points which were then transferred onto the wood samples studied for revealing external and internal asymmetry (Figure 2).

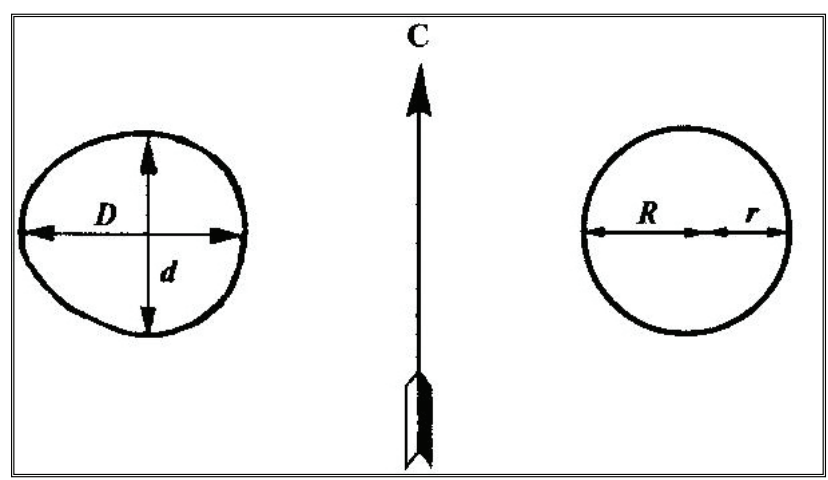

Figure 2:Trunk asymmetry factors(boon bias):

$$
\text { a - external asymmetry, Aext }=D / d \text {; }
$$$$
b \text { - internal asymmetry, Aint }=R / r
$$

External asymmetry,Aext,was defined as the ratio of $D$ maximum diameter (with indication of a direction in respect of the cardinal points) to $d$ minimum one (Figure 2, a). Internal asymmetry,Aint,(boon bias according to GOST 2140 'Flaws in wood')was studied through the ratio of $\mathrm{R}$ larger radius to $r$ smaller one at one and the same diameter strictly; basically, Aint characterizes the bias of medullary sheath from the trunk center (Figure 2, b). To perform these measurements the diameter was selected where there was a maximal difference in size of radii $R$ and $r$. Diameters and radii were measured in four directions: north-south (NS); eastwest (EW); south-east - north-west (SE$N W$ ); south-west - north-east (SW-NE).

Research into revealing the difference between the southern and northern sides of a trunk in respect of macrostructure, wood density and acoustic constant were carried out by means of cores selected with increment borers.

The method revealing standing resonant wood by means of cores has been researched rather recently $[3,4,9]$. For this purpose cross-section radial cores $4.0 \mathrm{~mm}$ in diameter were taken from the northern and southern sides of sample trees with an increment borer before cutting (Figure 3).

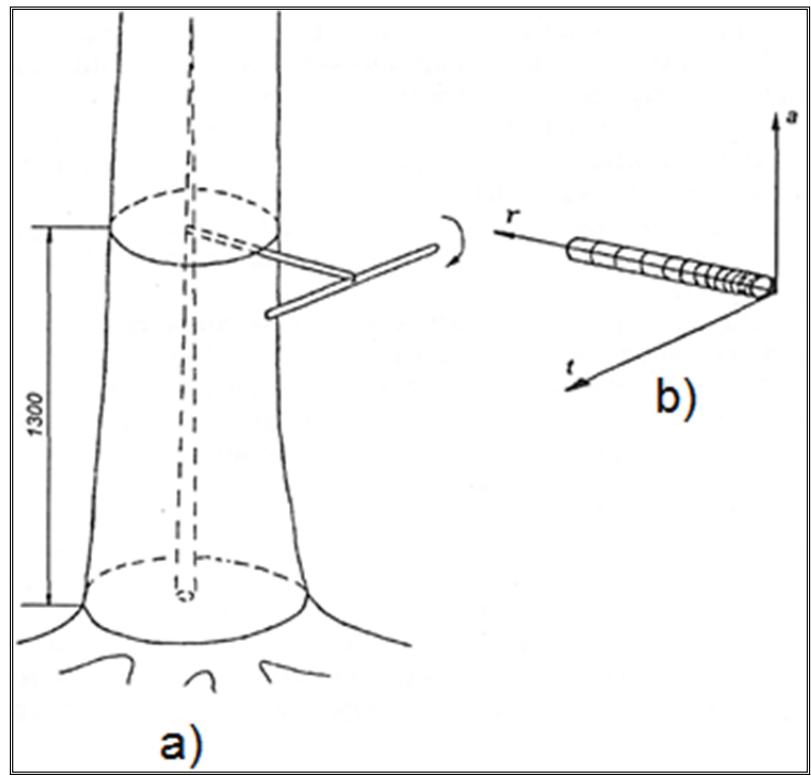

Figure 3: Wood (core) sampling from a standing tree with an increment borer: $a$ - on a tree; $b$ - main axes of core anisotropy

As a rule, wood structure along the length of a radial core is non-uniform and, accordingly, physical and mechanical parameters of heartwood and sapwood differ from each other. This difference is well appreciable even with the naked eye, first of all, because of the wood macrostructure: narrow annual growth layers in a peripheral zone of a trunk and wide ones close to juvenile zone(Figure 4, a). 


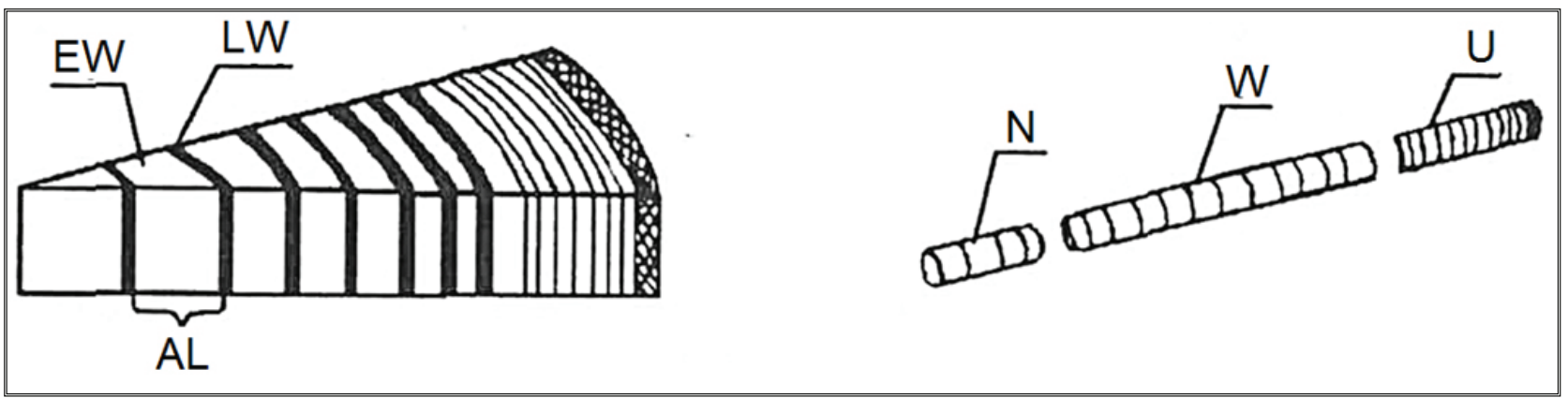

Figure 4:General view of wood macrostructure according to the trunk zone: a - elements of wood macrostructure (EW - early wood; $L W$ - late wood; $A L$ - annual layer); $b$ - scheme of core division according to zones

( $N$ - near-core zone; $W$ - working zone; U-undercork zone)

Generally, rather homogeneous wood between under cork and core zones is taken for deck manufacturing. Taking this fact into consideration, we studied this part of a trunk conditionally marked by letter W, Working zone, on cores (Figure 4, b).
Basic physical and dendroacoustical properties of wood, namely, humidity, density, macrostructure, velocity of ultrasound, were defined in laboratory environment. The general order of complex research is presented in Figure 5.

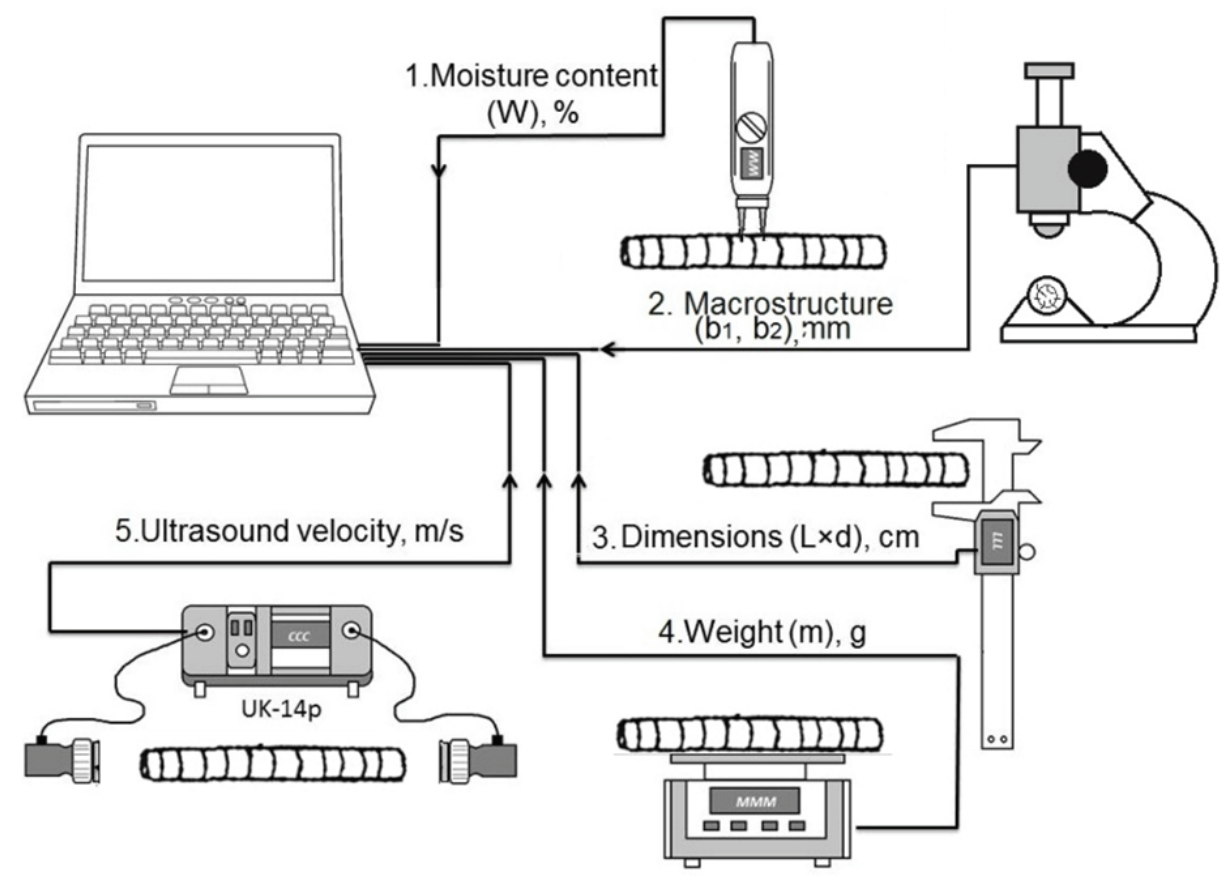

Figure 5: Principle diagram of experimental measurements

Wood macrostructure was studied with electronic dendrometer (Figure 5, 2. Macrostructure) which action principle is based on defining the width of early (b1) and late (b2) zones in annual rings according to their micro hardness [16]. Sound velocity in wood (C) was defined using pulse ultrasonic method through fixation of elastic longitudinal wave propagation time (T) along the sample (I):

$$
C=l / \tau
$$

It is necessary to note, that a piezoelectric transducer with $60 \mathrm{kHz}$ frequency was used in the device, which is optimal for wood studies. The sound velocity in the material and the material density, $\rho$, given, it is possible to define Young's dynamic modulus, $E$, from the following known ratio:

$C=\sqrt{\frac{E_{d y n}}{\rho}}, \quad$ then $E_{d y n}=C^{2} \cdot \rho$ 
It is known, that today acoustic constant of sound radiation (K) suggested by academician N.N. Andreyev [01] is accepted as basic criterion of 'musicality' of the given material in many countries:

$$
K=\sqrt{\frac{E}{\rho^{3}}}
$$

Note. Threshold value is $\mathrm{K} \geq 12.0 \mathrm{~m} 4 / \mathrm{kg} \cdot \mathrm{s}$ for resonant wood in a longitudinal direction along fibers, and under cross-section radial measurements $\mathrm{K} \geq 3.5 \mathrm{~m} 2 / \mathrm{kg} \cdot \mathrm{s}[08,19]$. Small transformations and joint solution of equations 2 and 3 allow to define the size of acoustic constant $K$ through $C$ and $\rho$ :

$$
\left\{\begin{array}{l}
K=\sqrt{\frac{E}{\rho^{3}}} \\
C=\sqrt{\frac{E}{\rho}}
\end{array} \Rightarrow K=\frac{C}{\rho}\right.
$$

Thus, the physical essence of resonant wood represents combination of incongruous properties, i.e., high indices of rigidity, sound velocity and low density. Variability of sound velocity in wood along the height of a trunk was studied on 16 newly felled spruce trees. For this purpose the velocity of ultrasonic signal across a trunk was measured at standard height of $1.3 \mathrm{~m}$ and at rela- tive levels of $0.2 \mathrm{H}, 0.5 \mathrm{H}$ and $0.7 \mathrm{H}$ with the help of УК-14П device; for best contact of piezoelectric transducers with wood the places of measurements were carefully cleared of bark and cambium. The diameter of spruce trees varied within the limits of $30-40 \mathrm{~cm}$ at breast height, and their height was $23-28 \mathrm{~m}$ (Figure 1).

At the moment of measurements wood moisture content humidity obviously exceeded the limit of saturation of its cellular walls, which allowed to make velocity calculations without correction for influence of humidity; physical and mechanical properties of wood depend almost not at all on its moisture content humidity above the given limit ( $W \approx 30 \%$ ). Sound velocity at relative heights of trees gives rather precise representation on the dynamics of resonant properties of wood along a trunk even without acoustic constants representation. This is due to the fact that according to formula 4 sound velocity at the given density of material predetermines its resonant properties; besides, the density of spruce wood in a longitudinal direction of a trunk varies insignificantly [17]. Since the diameter of a tree changes with its height, the nature of trunk diameter influence on cross-section sound velocity was studied simultaneously on the same 16 sample trees.

\begin{tabular}{|c|c|c|c|c|c|c|c|c|}
\hline \multirow{2}{*}{$\begin{array}{l}\text { tree (cut) index } \\
\text { number }\end{array}$} & \multicolumn{4}{|c|}{ External asymmetry } & \multicolumn{4}{|c|}{ Internal asymmetry } \\
\hline & $\begin{array}{l}\text { Asymmetry } \\
\text { direction }\end{array}$ & Д, mm & $\mathrm{d}, \mathrm{mm}$ & $A_{e x t}$ & $\begin{array}{l}\text { Asymmetry } \\
\text { direction }\end{array}$ & $\mathrm{R}, \mathrm{mm}$ & $\mathrm{r}, \mathrm{mm}$ & Aint \\
\hline *1-III & E-W & 417 & 408 & 1.02 & W-E & 218 & 199 & 1.10 \\
\hline $2-I I$ & SE-NW & 355 & 332 & 1.07 & N-S & 176 & 156 & 1.13 \\
\hline *3-II & SE-NW & 328 & 299 & 1.10 & SE-NW & 184 & 144 & 1.28 \\
\hline *4-I & SE-NW & 359 & 350 & 1.03 & SE-NW & 202 & 157 & 1.29 \\
\hline *5-I & N-S & 359 & 355 & 1.01 & N-S & 189 & 170 & 1.11 \\
\hline $6-I V$ & SE-NW & 336 & 328 & 1.02 & W-E & 180 & 149 & 1.21 \\
\hline${ }^{*} 6-\mathrm{V}$ & N-S & 319 & 317 & 1.01 & S-N & 169 & 150 & 1.13 \\
\hline $7-\mathrm{VII}$ & N-S & 299 & 290 & 1.03 & NW-SE & 162 & 135 & 1.20 \\
\hline $8-1$ & SE-NW & 332 & 326 & 1.02 & NE-SW & 174 & 152 & 1.14 \\
\hline $8-111$ & $E-W$ & 298 & 294 & 1.01 & NW-SE & 155 & 139 & 1.12 \\
\hline *9- II & SE-NW & 330 & 313 & 1.05 & NW-SE & 183 & 147 & 1.24 \\
\hline
\end{tabular}

Table 1: Spruce tree trunks asymmetry indices on separate cuts 
Notes. Index number of a cut coincides with relative height of its measurements on a trunk, e.g., I and II mean $0.1 \mathrm{H}$ and $0.2 \mathrm{H}$, accordingly. ${ }^{*}$ Cuts where the contingency of external and internal asymmetry of a trunk in one direction is found out.

Despite of some divergences, estimation of the data obtained by Student's test has not confirmed reliability of difference of average values of radii in all the directions measured.

Thus, thefollowing conclusionscanbedrawnbased on the results of spruce trunks asymmetry studies:

- there is no precise longitude-latitude regularities in formation of both external and internal asymmetry of spruce trunks; obviously, other factors come out here, e.g., light and wind modes, macro-and microexposition of the locality, tree inclination, etc. which in aggregate negate the influence of the cardinal points on asymmetry and corresponding physical and mechanical properties of wood formation

- internal asymmetry has a greater absolute value than external one, and they do not always coincide in direction: quite externally round trunks have explicit asymmetry in the position of medullary sheath;
- internal asymmetry along one and the same trunk can vary both in direction and in value. Quite probably, this is connected with the fact that during different periods of growth a tree is exposed to unequal impact of certain factors of the environment, and, as a consequence, convolute trunks are quite frequently formed which are rather well appreciable even by sight based upon the inclination of wood fibers; it is also possible to assume, that medullary sheath does not always remain strictly vertical, has small bias against the trunk axis during certain periods of tree growth for some reasons, but all this is necessary to be proved.

Macrostructure and acoustic constant of wood on the northern and southern sides of a trunk. Initial comparison of trees has shown that there are some differences in macrostructure and dendroacoustics on the northern and southern sides of a trunk. However these differences come out individually both on separate trunks and plots. For example, it is found out that on a plot with rather bad growth conditions (bilberry spruce forest) the contents of late wood on the northern side is less than on the southern one.

Table 2: Average indices of spruce tree trunks wood macrostructure and acoustic constant

\begin{tabular}{|c|c|c|c|}
\hline \multirow{2}{*}{ Index name } & \multirow{2}{*}{ Units of meas. } & Northern side & Southern side \\
\hline & & $X \pm T$ & $X \pm T$ \\
\hline $\begin{array}{l}\text { Tree ring width or } \\
\text { Anual ring width }\end{array}$ & $\mathrm{mm}$ & $1.63+0.02$ & $1.58+0.02$ \\
\hline Late wood content & $\%$ & $30.59 \pm 1.86$ & $30.83 \pm 2.02$ \\
\hline Acoustical constant & $\mathrm{m} 4 / \mathrm{kg} \cdot \mathrm{s}$ & $3.52+0.07$ & $3.41 \pm 0.09$ \\
\hline
\end{tabular}

Average data on the objects and trees are given in Table 2.

Note. The indices of acoustic constant are given for standard moisture content of wood, $\mathrm{W}=$ $12 \%$.

Based on the research results, it is possible to note that macrostructure and acoustic constants of wood at a certain height inside trunks have, on the average, identical indices irrespective of the cardinal points.

The check of uniformity of the data obtained by Student's test at 0.05 level of significance have confirmed the absence of authentic difference in these indices on the northern and southern sides of spruce trees.
Change of sound cross-section velocity in wood along the tree height and depending on its diameter. The research results show that the velocity of sound in wood across the trunk depends on individual peculiarities of trees and can vary within the limits of $1000-1800 \mathrm{~m} / \mathrm{s}$; the factor of variation amounts to about $35 \%$.

There is a certain regularity of increase in sound velocity moving from the stem base to the top, which is expressed through first order equation $y=143.0 x+66.3$; this regularity is illustrated in Figure 6. 




Figure 6: Changing of sound cross-section velocity in wood along the trunk height

Unfortunately, the opportunity of longitudinal selection of the given material is essentially limited in comparison with cross-section selection, especially last years in connection with reduction of resonant spruce trunk thickness. Nevertheless, carrying out acoustical diagnostics and maximal use of resonant wood on the length of for\) $0.2 \mathrm{H}: C=1303.1+11.01 D_{2}-0.162 D^{2}{ }_{2}$

\) $0.5 \mathrm{H}: C=1057.1+30.48 D_{5}-0.516 D^{2}{ }_{5}$

\) $0.7 \mathrm{H}: C=1399.9+9.52 D_{7}-0.246 D^{2}{ }_{7}$ est products gains special practical value now. Relationship of sound velocity in wood and biometric data of a trunk. To study this question, diameters of a trunk at height of $1.3 \mathrm{~m}$ (D1.3) and at relative heights $0.2 \mathrm{H}, 0.5 \mathrm{H}$ and $0.7 \mathrm{H}$ (D02, D05, D07, accordingly) are taken as analyzed indices.

Due to significant dispersion of the results of measuring ultrasound velocity in wood across trunks (by diameter), we consider only one-factorial quadratic equations of regression, as artificial increase of equations accuracy at the expense of their complication will reflect casual fluctuations of control points. The nature of trunk diameter impact on sound velocity at different levels of its height is expressed through the following parabolic equations (their graphic representation is given in Figure 7): at the height of $1.3 \mathrm{~m}$ :

$$
C=1184.8+15.4 D_{1.3}-0.192 D^{2} 1.3
$$

Note: The diameter ismeasured strictly in NS direction.

Check of the results obtained against Fisher's ratio test has shown that all equations of regression are $\mathrm{n}$ ot significant. Hence, it is possible to speak about the absence of total regularity of trunk diameter impact on sound velocity. C-curves have little difference in nature depending on diameters of a trunk at different levels, i.e. the degree of relationship is practically identical here; obviously, except for an absolute diameter value there are other factors which give rather significant dispersion of velocity of ultrasonic signal passing across the tree trunk. 


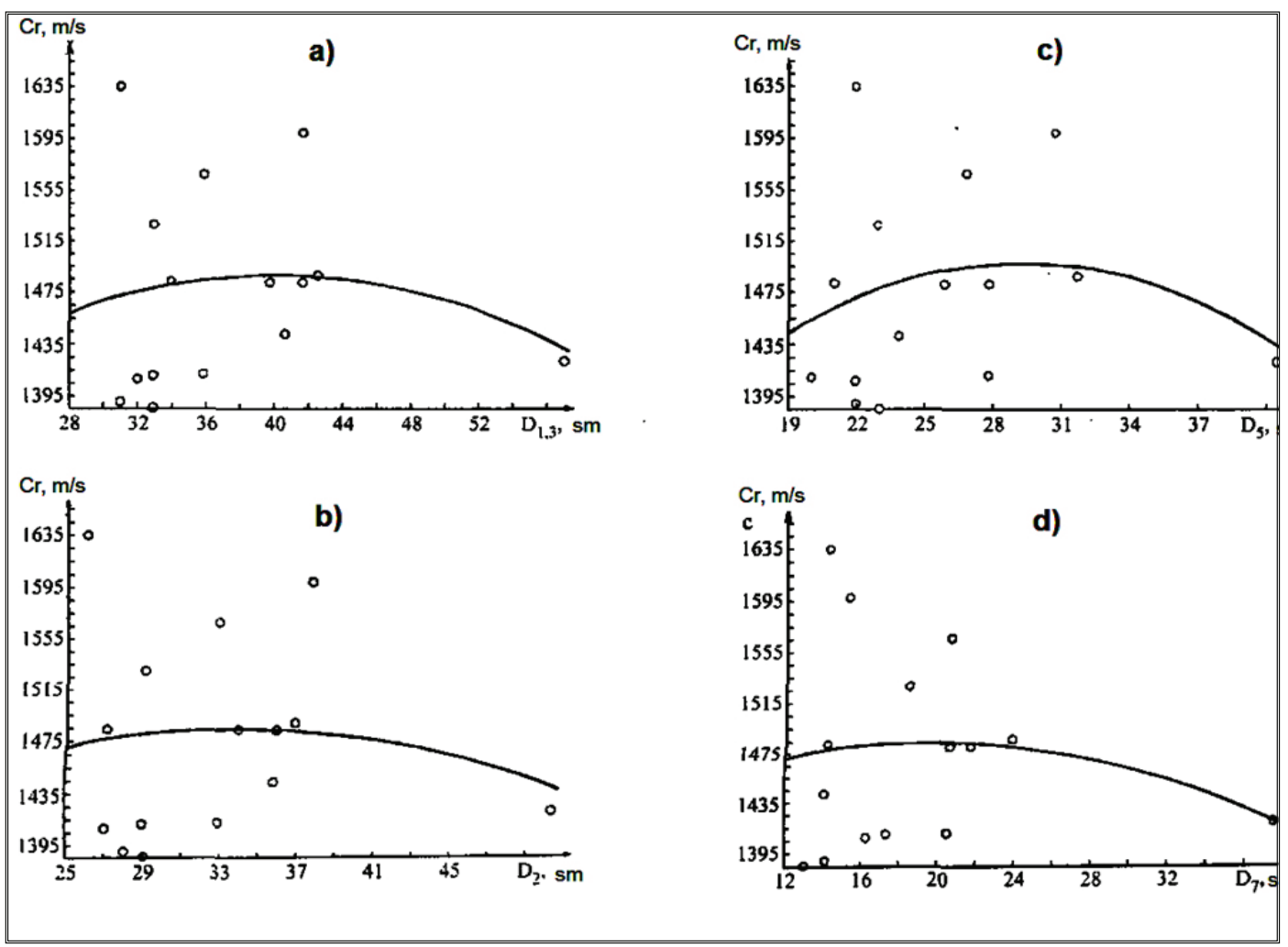

Figure 7: Dependence of sound velocity on trunk diameter at its different levels: $a$ - at the height of $1.3 \mathrm{~m} ; b-0.2 \mathrm{H} ; \mathrm{c}-0.5 \mathrm{H} ; \mathrm{d}-0.7 \mathrm{H}$

\section{CONCLUSION}

On this stage of research the basic conclusion consists in the fact that obligatory use of wood from the northern side of a tree trunk cannot be considered a common rule and criterion for manufacturing decks of musical instruments; however, in certain growing conditions, trees can have the best resonant wood on the northern side in comparison with other sides of a tree trunk.

Hence, despite the lack of regularity in formation of dendroacoustic properties in respect of the cardinal points, one should not ignore the technique of wood selection for manufacturing musical instruments accepted by ancient masters (using separate sectors of a trunk). Even in case of absence of difference in acoustic parameters, the instrument made of wood from one trunk sector gives somewhat greater effect than the one made of wood from other parts of a trunk; it is known that selection of monogamous material is of especially great value for manufacturing so-called custom-made instruments with unique acoustic properties required [20].The top part of a trunk differs from the bottom one in better acoustic properties. The results obtained mainly confirm the existing opinions of scientists and experts that long ago, when there were opportunities to select rather thick spruce trees, masters, as a rule, used to collect wood at 4-6 m apart the spruce stem base for manufacturing decks of musical instruments [15].

In case of necessity to take strictly radial cores as test samples for carrying out scientific research, it is not enough to be guided by the generatrix forming a trunk, and repetitive coring along mutually perpendicular radii is required. If it is required to be limited to one drilling, it is necessary to use indicating transducers for defining the boon position. The main thing, in both cases it is necessary to specify the direction of drilling on a core with respect to the cardinal points, and in order to obtain reliable results it is expedient to analyze identical samples, e.g., taken only from the northern side of a trunk. 


\section{REFERENCES}

1) Andreyev, N.N. (1938). On the tree for musical instruments. Moscow: CMSRL.

2) Aturina, N.V. (1937). Study of the microscopic structure of the resonant spruce (Picea excels Link) with regard to its technical features. St. Petersburg.

3) Bucur, V. (1983). An ultrasonic method for measuring the elastic constants of wood increment cores bored from living trees. Ultrasonic, 116-126.

4) Bucur, V. (2006). Acoustics of Wood. Berlin: SpringerVerlag.

5) Blskova, G., \& Brdarov, N. (2003). Sounding wood acoustic characteristics studies. U: Collection of scientific reports at 50th anniversary of the Forest Engineering Institute, Woodworking and furniture production section, Sofia. 49-53.

6) Fabisiak, E. (2005). Variability of the basic anatomic elements and wood density in selected wood species. Rozprawy Naukowe.

7) Fedyukov, V.I., Saldaeva, E.Y., Tsvetkova, E.M., \& ChavchavadzeE.S., (2016). Resonance wood microstructure peculiarities. Wood Research, 61(3), 413-422.

8) Fedyukov, V.I., Shurgin, A.I., Saldaeva, E.Y., \& Tsvetkova, E.M. (2015). Theoretical studies and measurements of elastic-acoustic performance of wood with different methods for selection of resonant growing crop. Wood Research, 60(3), 417-428.

9) Fedyukov, V.I., \& Makaryeva, T.A. (1992). The diametrical rod as object for nondestructive method resilient-viscous characteristics definition of standing and sawn resonant wood. U: Proceedings actes working session de travaill, Nancy, France. 344-345.
10) Fuhr, K. (1926). Die akustischen Intsel der Geige. Verlag von Carl Markg.

11) Ille, R. (1979). Rezonaromidiavosmrku pro mistrovskflhousle. Dinvo, 34, 303-304.

12) Klisz, M., Ukalska, J., \& Wojda, T. (2014). Radial growth of selected stands of back locust in Poland. Ann. Warsaw Univ. Life Sci. Forest. And Wood Technol, 85, 123-130.

13) Kossovich, N.L. (1935). Research into the differences of wood anatomy structure on northern and southern sides of a coniferous tree trunk. Botanical journal, 20(5), 455-472.

14) Krishtofovich, A.N. (1932). Fossil forests as indicators of cardinal points position in the geological past and displacement theory of Wegener. Proc. Of the Academy of Sciences of the USSR, 3, 415-433.

15) Kuznetsov, I.I. (1930). Resonant wood and deck. Forestry and forestry, 42-44.

16) Fedyukov, V.I., \& Veselov L.N., (1999). Pat. 2130611 RU Method for resonant wood properties diagnostics and a device for its application. Bul. of invent., 4,

17) Polouboyarinov, O.I. (1976). Wood density. Moscow: Forestry.

18) Rajcan, E. (1990). Die Physikalisch - akustischencharakteristiken von holzals material fur die production von streichinstrumenten. $\mathrm{U}$ : Latest achievements in research of wood structure and physics, Zvolen.

19) Ugolev, B.N. (2001). Wood-forest with the basics of merchandising. Moscow.

20) Vitachek, E.F. (1964). Essays on the History of manufacture of stringed instruments.Moscow: Music.

Paper sent to revision: 10.02.2017.

Paper ready for publication: 21.03.2017. 